\title{
Maatalouden kasvihuonekaasupäästöt
}

\author{
Paula Perälä ${ }^{1)}$, Kristiina Regina ${ }^{2)}$ ja Martti Esala ${ }^{3)}$ \\ ${ }^{1)}$ MTT Ympäristöntutkimus, Maaperä ja ympäristö,31600Jokioinen, paula.perala@mtt.fi \\ ${ }^{2)}$ MTT Ympäristöntutkimus, kristiina.regina@mtt.fi \\ ${ }^{3)}$ MTT Ympäristöntutkimus, martti.esala@mtt.fi
}

\section{Johdanto}

Ihminen lisää toimillaan kasvihuonekaasujen määrää ilmakehässä (IPCC 2001). Merkittävimmät ihmisen toiminnan seurauksena ilmakehään joutuvat kasvihuonekaasut ovat hiilidioksidi $\left(\mathrm{CO}_{2}\right)$, dityppioksidi $\left(\mathrm{N}_{2} \mathrm{O}\right)$, metaani $\left(\mathrm{CH}_{4}\right)$ sekä niinkutsutut F-kaasut eli halogenoidut hiilivedyt, joita ovat HFC-yhdisteet (fluorihiilivedyt), PFC-yhdisteet (perfluorihiilivedyt) ja rikkiheksafluoridi. Kasvihuonekaasujen määrää ilmakehässä pyritään rajoittamaan kansainvälisillä sopimuksilla. YK:n ilmastosopimuksen (UNFCCC, United Nations Framework Convention on Climate Change, voimaan vuonna 1994) tavoitteena on vakiinnuttaa kasvihuonekaasupäästöjen pitoisuudet ilmakehässä sellaiselle tasolle, josta ei aiheudu vaarallisia häiriöitä ilmastojärjestelmässä. Ilmastosopimuksen Kioton pöytäkirja velvoittaa teollisuusmaita vähentämään kasvihuonekaasupäästöjään keskimäärin 5.2 \% vuoden 1990 tasosta ensimmäisellä velvoitekaudella 2008-2012. Suomen tavoitteena on vakiinnuttaa päästöt vuoden 1990 tasolle. (YM 2003a).

YK:n ilmastosopimuksen sopimusosapuolilla on velvollisuus laatia vuosittain inventaario tärkeimpien kasvihuonekaasupäästöjen lähteistä ja nieluista. Kioton pöytäkirja velvoittaa sen allekirjoittaneita maita myös luomaan kansallisen kasvihuonekaasupäästöjen laskentajärjestelmän. Kioton pöytäkirjan velvoitteiden mukaisesti raportoidaan vuosittain kansalliset $\mathrm{CO}_{2}, \mathrm{~N}_{2} \mathrm{O}, \mathrm{CH}_{4}$, sekä F-kaasujen päästöt YK:n ilmastosopimuksen sihteeristölle ja Euroopan yhteisöjen komissiolle. Raportoinnissa käytetään tarkoitukseen laadittuja CRF-tauluja (Common Reporting Format). Inventaariosta laaditaan raportti (National Inventory Report), jossa kuvataan laskentamenetelmät sekä käytetyt päästökertoimet. (YM 2003a;YM 2003b). Lisäksi laaditaan 3-4 vuoden välein maaraportti (UNFCCC 2001). Ilmastosopimuksen sihteeristö vastaa inventaarioiden ja maaraporttien tarkastuksista. Tarkastukset voivat tapahtua ns. keskitettyinä tarkastuksina (centralized review), työpöytätarkastuksina (desk review) tai maakäyntinä (country review) (Oinonen 2003).

Suomen kansallisen kasvihuonekaasuinventaarion toteuttajia ovat Tilastokeskus, Metsäntutkimuslaitos, Suomen ympäristökeskus, Valtion teknillinen tutkimuslaitos (VTT) sekä Maaja elintarviketalouden tutkimuskeskus (MTT) (YM 2002). Maatalouden kasvihuonekaasuinventaariota on kehittetty VTT:ssa. Vuonna 2001 vastuu maatalouden kasvihuonekaasuinventaarion toteuttamisesta ja kehittämisestä siirtyi MTT:1le.

\begin{abstract}
Aineisto ja menetelmät
Maatalouden aiheuttamat kasvihuonekaasupäästöt tunnetaan heikommin kuin muiden sektoreiden päästöt. Maatalouden tärkeimmät kasvihuonekaasut ovat dityppioksidi, metaani ja hiilidioksidi. Päästöjä syntyy maatalousmaassa, lannankäsittelyn seurauksena sekä kotieläinten ruoansulatuskanavassa (mm. Kulmala \& Esala 2000; Pipatti 1994; Pipatti 1997; Pipatti et al. 2000). Erityisesti maatalousmaassa syntyvät hiilidioksidi- ja dityppioksidipäästöt tunnetaan huonosti (MMM 2001). Kasvihuonekaasupäästöjä syntyy maataloudessa myös energian käytön (tuotantorakennusten lämmitys, työkoneet) sekä erilaisten teollisuudessa valmistettujen tuotteiden käytön (väkilannoitteet) seurauksena, mutta ne lasketaan kasvihuonekaasuinventaariossa osana energiasektorin päästöjä (MMM 2001;YM 2003b). Maatalouden kasvihuonekaasuinventaariossa lasketaan vuosittainen arvio kotieläinten ruoansulatuksen metaanipäästöistä, lannankäsittelyn metaanipäästöistä, lannankäsittelyn dityppioksidipäästöistä, maatalousmaiden dityppioksidipäästöistä sekä maatalousmaiden hiilidioksidipäästöistä. Laskennassa käytetään VTT:ssä kehitettyä mallia (Pipatti 2001), joka perustuu IPCC:n (Intergovernmental Panel on Climate Change) laatimiin ohjeisiin (IPCC 1996a,b; Penman et al. 2000). Kasvihuonekaasuinventaarion suorittamiseksi tarvitaan erilaisia lähtötietoja kuten eri eläinlajien lukumäärä- sekä viljelykasvien pinta-ala- ja satomäärätietoja. Inventaariossa tarvittava aktiviteettidata saadaan erilaisista lähteistä kuten kirjallisuudesta, tietokannoista ja asiantuntijoilta.
\end{abstract}


Lisäksi tarvitaan muita parametreja ja päästökertoimia, jotka perustuvat joko IPCC:n oletusarvoihin tai kansalliseen dataan, esimerkiksi kirjallisuuteen tai asiantuntija-arvioon. Laskennassa käytettyjä päästökertoimia on lueteltu talukossa 1. Päästöt ilmoitetaan giga- tai teragrammoina. Ne voidaan ilmoittaa myös hiilidioksidiekvivalentteina, jolloin kunkin kaasun päästö kerrotaan sille ominaisella GWP-kertoimella (Global Warming Potential). GWP-kerroin kuvaa kaasun lämmityspotentiaalia suhteessa hiilidioksidiin. Vuoden 2001 inventaariossa käytettiin metaanille kerrointa 21 ja dityppioksidille 310 .

Maatalouden päästöjen epävarmuus on suuri. Avainpäästölähteillä on suurin vaikutus inventaarion epävarmuuteen. Avainpäästölähteeksi kutsutaan päästölähdettä, jonka osuus suorien kasvihuonekaasujen päästöistä on merkittävä joko päästöjen määrän, kehityksen tai molempien vuoksi (Pipatti 2001). Epävarmuusanalyysin avulla voidaan tunnistaa avainpäästölähteet, parantaa inventaarion tarkkuutta ja kohdistaa päästöjen vähentämistoimet merkittävimpiin päästölähdeluokkiin (Monni \& Syri 2003;Aaltonen et al. 2001).

Vuoden 2001 YK:n ilmastosopimuksen sihteeristölle raportoidut päästöt laskettiin MTT:ssa (YM 2003b). Tulosten epävarmuustarkastelu ja avainpäästölähteiden arviointi tehtiin VTT:ssa (Monni \& Syri 2003).

Taulukko 1. Esimerkkejä v. 2001 inventaariossa käytetyistä päästökertoimista (YM 2003b).

\begin{tabular}{|l|l|l|l|l|}
\hline Päästölähdeluokka & Päästölähde & Päästökerroin & Yksikkö & Tyyppi \\
\hline $\begin{array}{l}\mathrm{CH}_{4} \text { kotieläinten } \\
\text { ruoansulatus }\end{array}$ & lypsylehmä & 114 & $\mathrm{~kg} \mathrm{CH} /$ eläin/vuosi & kansallinen \\
\hline & hevonen & 18 & $\mathrm{~kg} \mathrm{CH}_{4} /$ eläin/vuosi & IPCC:n oletusarvo \\
\hline & lammas & 8 & $\mathrm{~kg} \mathrm{CH}_{4} /$ eläin/vuosi & IPCC:n oletusarvo \\
\hline $\mathrm{CH}_{4}$ lannankäsittely & lypsylehmä & 8.31 & $\mathrm{~kg} \mathrm{CH}_{4} /$ eläin/vuosi & kansallinen \\
\hline & hevonen & 1.42 & $\mathrm{~kg} \mathrm{CH} / /$ eläin/vuosi & kansallinen \\
\hline & lammas & 0.19 & $\mathrm{~kg} \mathrm{CH}_{4} /$ eläin/vuosi & kansallinen \\
\hline $\mathrm{N}_{2} \mathrm{O}$ lannankäsittely & lietelanta & 0.001 & $\mathrm{~kg} \mathrm{~N}_{2} \mathrm{O}-\mathrm{N} / \mathrm{kg} \mathrm{N}$ & IPCC:n oletusarvo \\
\hline & kuivikelanta & 0.02 & $\mathrm{~kg} \mathrm{~N}_{2} \mathrm{O}-\mathrm{N} / \mathrm{kg} \mathrm{N}$ & IPCC:n oletusarvo \\
\hline & laidun & 0.02 & $\mathrm{~kg} \mathrm{~N}_{2} \mathrm{O}-\mathrm{N} / \mathrm{kg} \mathrm{N}$ & IPCC:n oletusarvo \\
\hline $\mathrm{N}_{2} \mathrm{O}$ maatalousmaat & väkilannoitteet & 0.0125 & $\mathrm{~kg} \mathrm{~N}_{2} \mathrm{O}-\mathrm{N} / \mathrm{kg} \mathrm{N}$ & IPCC:n oletusarvo \\
\hline & lanta & 0.0125 & $\mathrm{~kg} \mathrm{~N}_{2} \mathrm{O}-\mathrm{N} / \mathrm{kg} \mathrm{N}$ & IPCC:n oletusarvo \\
\hline & $\begin{array}{l}\text { orgaanisten } \\
\text { maiden viljely }\end{array}$ & 8 & $\mathrm{~kg} \mathrm{~N}_{2} \mathrm{O}-\mathrm{N} / \mathrm{ha} / \mathrm{vuosi}$ & IPCC:n oletusarvo \\
\hline
\end{tabular}

\section{Tulokset ja tulosten tarkastelu}

Suomen maatalouden kasvihuonekaasupäästöt $\mathrm{CO}_{2}$-ekvivalenteiksi muutettuna olivat $7.45 \mathrm{Tg}$ vuonna 2001 ( 1 teragramma=miljoona tonnia). Metaanipäästöt olivat yhteensä $1.76 \mathrm{Tg}$, josta kotieläinten ruoansulatuksen osuus oli $1.56 \mathrm{Tg}$ ja lannankäsittelyn $0.20 \mathrm{Tg}$. Dityppioksidipäästöt olivat yhteensä $3.74 \mathrm{Tg}$, josta maatalousmaiden osuus oli $3.34 \mathrm{Tg}$ ja lannankäsittelyn osuus $0.40 \mathrm{Tg}$. Hiilidioksidipäästöt olivat yhteensä $1.95 \mathrm{Tg}$. Hiilidioksidipäästöiksi lasketaan maatalousmaasta tulevat hiilidioksidipäästöt, joista orgaanisten maiden hiilidioksidipäästöjen osuus oli $1.25 \mathrm{Tg}$, kivennäismaiden hiilidioksidipäästöjen osuus $0.31 \mathrm{Tg}$ ja kalkituksen aiheuttamien hiilidioksidipäästöjen osuus $0.39 \mathrm{Tg}$. Maatalouden energian käytön seurauksena syntyvät päästöt lasketaan osana energiasektorin päästöjä, joten niitä ei huomioida laskelmissa. Suomen kasvihuonekaasupäästöjen kokonaismäärä vuonna 2001 oli $80.9 \mathrm{Tg}$ (ilman maankäytön muutosten ja metsien aiheuttamaa hiilinielua). Maatalouden osuus kokonaispäästöistä oli $9.2 \%$ vuonna 2001 . Hiilidioksidipäästöistä maatalouden osuus oli $2.9 \%$, dityppioksidipäästöistä $52.6 \quad \%$ ja metaanipäästöistä $33.0 \%$ vuonna 2001. (YM 2003b). Maataloussektorilla avainpäästölähteiksi tunnistettiin maatalousmaiden ja lannankäsittelyn $\mathrm{N}_{2} \mathrm{O}$-päästöt sekä kotieläinten ruoansulatuksen $\mathrm{CH}_{4}$ päästöt (Monni \& Syri 2003). Epävarmuustarkastelun tuloksena saatiin maataloussektorin epävarmuudeksi $-37 \ldots+47 \%$ (Monni \& Syri 2003). 


\section{Johtopäätökset}

Tulosten perusteella maatalouden kasvihuonekaasupäästöt vähenivät $10.10 \mathrm{Tg}$ :sta $7.45 \mathrm{Tg}$ :aan ajalla 1990-2001. Lähtötiedoissa tuona aikana tapahtuneet muutokset, kuten eläinmäärien väheneminen, maaperään tulevan typpikuormituksen väheneminen sekä orgaanisten maiden viljelypinta-alan väheneminen vaikuttavat päästöjen kehitykseen. Maataloudesta tulevien, hyvin heterogeenisten päästöjen arvioinnissa yksinkertainen malli ei välttämättä vastaa todellisuutta. Suurimmat epävarmuudet liittyvät maatalousmaiden päästöihin. Mallin sisältämistä parametreista useat ovat IPCC:n oletusarvoja. Suurin osa päästökertoimista on tällä hetkellä IPCC:n oletuskertoimia, koska kansallista mittausdataa ei ole riittävästi saatavilla. IPCC:n parametrien ja päästökerrointen soveltuvuudesta Suomen oloihin ei ole riittävästi tietoa. Inventaarion epävarmuutta lisää puutteelliset tiedot viljelyssä olevien orgaanisten maiden pinta-alasta. Mallin kehittäminen on tarpeen, jotta päästöjen suurutta ja epävarmuutta voidaan arvioida luotettavammin. Kotimaisen mittausdatan kerääminen sekä kotimainen ja kansainvälinen yhteistyö menetelmäkehityksessä ovat avainasemassa. Vuosittaisten inventaariotietojen lisäksi maatalouden päästöjen kehityksestä tarvitaan ennusteita. Muita kehittämistarpeita ovat käytännön inventaariotyön ja raportoinnin kehittäminen, sekä laatu- ja epävarmuustyö. Kansainväliset velvoitteet raportoinnin ja laadunvarmistuksen suhteen vaativat resursseja. Parhaiten inventaariota voidaankin kehittää, kun se tapahtuu useiden tahojen välisenä yhteistyönä.

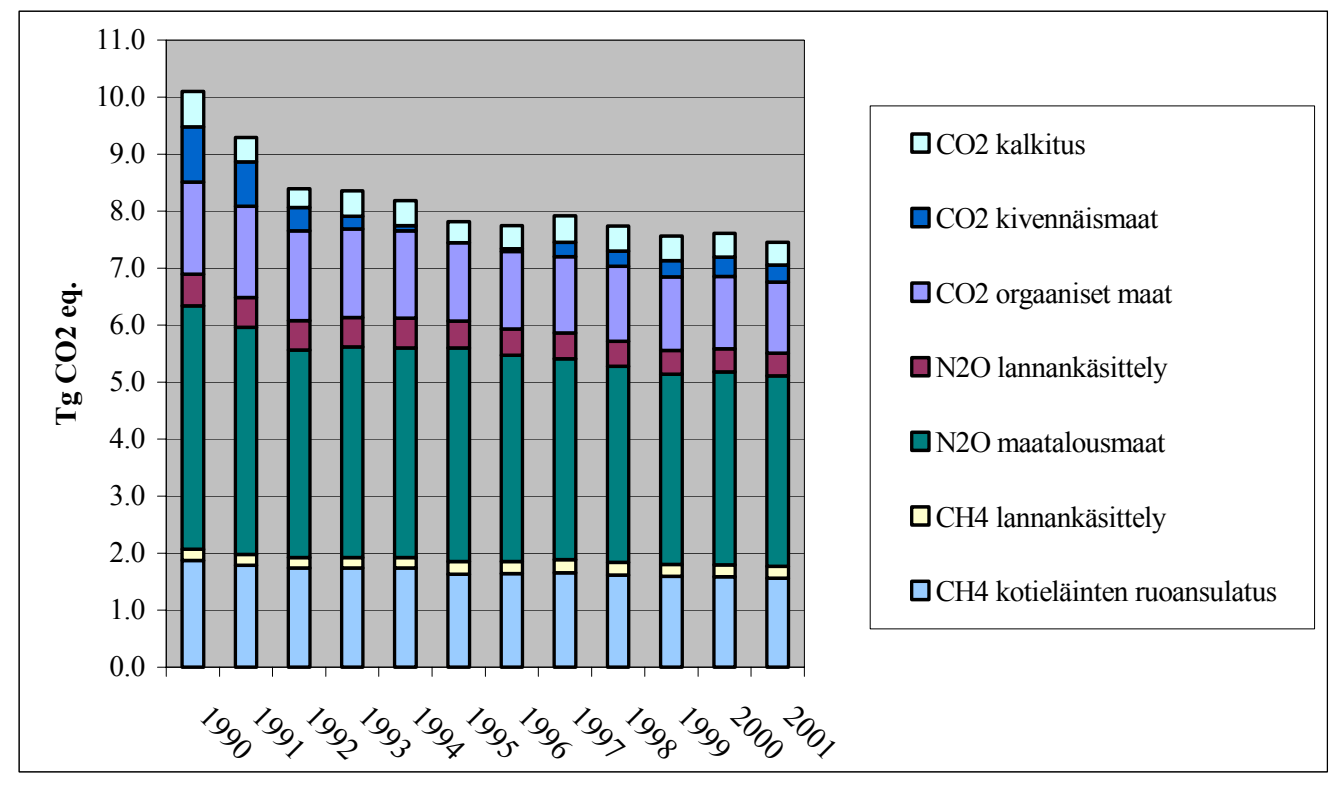

Kuva 1. Suomen maatalouden kasvihuonekaasupäästöjen kehitys vuosina 1990-2001 (YM 2003b).

\section{Kirjallisuus}

Aaltonen, J., Palosuo, T. \& Pipatti, R. 2001. Key source identification in the Finnish 1999 greenhouse gas inventory. VTT Energy Reports 34/2001. 28 p.

IPCC 1996a. Revised 1996 IPCC Guidelines for National Greenhouse Gas Inventories. Reference Manual. http://www.ipcc-nggip.iges.or.jp/public/gl/invs6.htm

IPCC 1996b. Revised 1996 IPCC Guidelines for National Greenhouse Gas Inventories. Workbook. http://www.ipcc-nggip.iges.or.jp/public/gl/invs5.htm

IPCC 2001. Climate change 2001: The Scientific Basis. Contribution of Working Group I to the Third Assessment Report of the Intergovernmental Panel on Climate Change. J.T. Houghton, Y. Ding, D.J. Griggs, M. Noguer, P.J. van der Linden and D. Xiaosu. Cambridge University Press, Cambridge.

Kulmala A. \& Esala M. 2000. Maatalous ja kasvihuonekaasupäästöt. Kirjallisuuskatsaus. Maatalouden tutkimuskeskuksen julkaisuja. Sarja A:76. Jokioinen: Maatalouden tutkimuskeskus. $67 \mathrm{~s}$.

MMM 2001. Maatalouden kehitysarvio kansallista ilmasto-ohjelmaa varten. Maa- ja metsätalousministeriö. Työryhmämuistio MMM 2001:2. Helsinki. 
Monni, S. \& Syri, S. 2003.Uncertainties in the Finnish 2001 Greenhouse Gas Emission Inventory. Espoo 2003. VTT Research Notes 2209.101p.+ app.27p.

Oinonen, T. 2003. Inventaarien tarkastaminen ja tarkastajien koulutus. Kaasutyöryhmän seminaari 5.5.2003. Scandic Hotel Continental, Helsinki.

Penman, J., Kruger, D., Galbally, I., Hiraishi, T., Nyenzi, B., Emmanuel, S., Buendia, L., Hoppaus, R., Martinsen, T., Meijer, J., Miwa, K. and Tanabe, K. 2000. Good Practice Guidance and Uncertainty Management in National Greenhouse Gas Inventories. Hayama: Intergovernmental Panel on Climate Change (IPCC). http://www.ipcc-nggip.iges.or.jp/public/gp/gpgaum.htm

Pipatti R., Tuhkanen S., Mälkiä P. \& Pietilä R. 2000. Maatalouden kasvihuonekaasupäästöt sekä päästöjen vähentämisen mahdollisuudet ja kustannustehokkuus. VTT:n julkaisuja $841.72 \mathrm{s.}$ http://www.inf.vtt.fi/pdf/julkaisut/2000/J841.pdf

Pipatti, R. 1994. Metaanin ja typpioksiduulin päästöarviot, päästöjen kehitys ja rajoituspotentiaali. VTT:n tiedotteita $1548.68 \mathrm{~s}$.

Pipatti, R. 1997. Suomen metaani ja dityppioksidipäästöjen rajoittamisen mahdollisuudet ja kustannustehokkuus. VTT:n tiedotteita 1835. 62 s+liitteet.

http://www.inf.vtt.fi/pdf/tiedotteet/1997/T1835.pdf

Pipatti, R. 2001. Greenhouse gas emissions and removals in Finland. VTT Research Notes 2094. 59 p. + app. 95p. Technical Research Centre of Finland. http://www.vyh.fi/eng/environ/state/air/emis/ghg/methodol.pdf UNFCCC 2001. Finland's Third National Communication Under The United Nations Framework Convention On Climate Change. Saatavissa UNFCCC:n internet-sivuilta http://unfccc.int/resource/docs/natc/finnc3.pdf YM 2002. Kaasutyöryhmän loppuraportti. Kehittämisehdotuksia kansalliseksi järjestelmäksi koskien kasvihuonekaasupäästötietojen laskemista. Suomen Ympäristö 548. Ympäristöministeriö. Helsinki. http://www.vyh.fi/palvelut/julkaisu/elektro/sy548/sy548.pdf

YM 2003a. Kioton pöytäkirjan toimeenpanon säännöt. Suomen ympäristö 607. Ympäristöministeriö. Helsinki 2003. http://www.ymparisto.fi/palvelut/julkaisu/elektro/sy607/sy607.htm

YM 2003b. Greenhouse gas emissions from Finland 1990-2001. National inventory report to the UNFCCC Secretariat. Ympäristöministeriö, Helsinki. http://www.ymparisto.fi/eng/environ/state/air/emis/ghg/NIR 03.pdf 